\title{
EDUCAÇÃO AMBIENTAL CRÍTICA, DA TEORIA À PRÁTICA ESCOLAR: ANÁLISE DA EXPERIÊNCIA DE UM PROJETO NO CONTEXTO DE UMA ESCOLA PÚBLICA DO RIO DE JANEIRO
}

Paolo de Castro Martins Massoni ${ }^{1}$

Ana Carolina Souza da Silva ${ }^{2}$

Diogo Majerowicz Maneschy ${ }^{3}$

Celso Sánchez Pereira ${ }^{4}$ Monica Cardoso Ambivero 5

Alexandre Ferreira Lopes $^{6}$

Resumo: Este trabalho investigou as possibilidades da inserção da Educação ambiental (EA) em uma escola pública, bem como suas potencialidades e desafios, tendo como base teórica a EA crítica. A metodologia utilizada foi a Pesquisa Participante. Os fatores limitantes constatados para a inserção da EA crítica foram a fragilidade na formação docente, a não inserção da EA no Projeto Político Pedagógico da escola, a forte presença de projetos que reproduzem o paradigma hegemônico da sociedade capitalista, entre outros. As principais potencialidades constatadas são a inserção da EA no PPP escolar elaborado de forma coletiva, a garantia de formação continuada dos professores, articulação com a comunidade local e a realização da EA de forma disciplinar.

Palavras-chave: Educação Ambiental em Espaços Escolares; Educação Ambiental Crítica; Projeto Político Pedagógico.

2 Universidade Federal do Rio de Janeiro. E-mail: ana.ssouza15@gmail.com.

3 Instituto Permacultura Lab. E-mail: diogommaneschy@gmail.com

4 Universidade Federal do Estado do Rio de Janeiro. E-mail: celso.sanchez@hotmail.com

${ }^{5}$ E-mail: ambivero@gmail.com

6 Universidade Federal Rural do Rio de Janeiro. E-mail: alexandrelopes@outlook.com

Revbea, São Paulo, V. 14, No 2: 86-102, 2019. 


\section{Introdução}

O presente artigo tem como tema a educação ambiental (EA) desenvolvida no âmbito escolar a partir de atividades que envolveram estudantes e professores em uma escola pública. Dessa maneira, este trabalho analisa as atividades desenvolvidas por um grupo de estudos e atividades teóricas e práticas que ocorreram no contraturno de uma escola estadual do Rio de Janeiro, composto por estudantes do ensino médio, e que teve como base os pressupostos teóricos da EA crítica. Tal análise fez parte de uma pesquisa de mestrado realizada no ano de 2014, que investigou ainda as potencialidades e desafios encontrados por outros pesquisadores que investigaram a EA no contexto escolar.

O termo "ambiental" associado à educação possui um caráter histórico (TEIXEIRA et al., 2013) e teve seu desenvolvimento favorecido em decorrência da busca por respostas e soluções para o enfrentamento da crise ambiental (LAYRARGUES, 2012; TEIXEIRA et al., 2013), juntamente com o surgimento de novos valores éticos em relação a essa problemática (LIMA, 2011). Dessa maneira, têm-se uma esperança de que a educação, principalmente a oferecida na escola, possa ajudar as pessoas a enfrentarem de forma mais instrumentalizada sua realidade através da reflexão e ação sobre os fenômenos sociais (VELOSO, 2007). A expectativa da sociedade em relação à escola gerou como resposta a crescente disseminação da EA nas escolas brasileiras (GUIMARÃES, 2012). Entretanto, práticas muito diferentes sob as perspectivas ideológica e pedagógica são chamadas de EA, o que torna imprescindível situar as bases conceituais que as fundamentam enquanto projeto de educação (CARVALHO, 2004).

Até os anos 1980, existiu uma forte tendência que ainda se faz presente em discursos de grandes empresas e meios de comunicação como internet e televisão, de que a EA deveria se basear no ensino de conteúdos biológicos e na transmissão de condutas ecologicamente corretas, levando a uma mudança de comportamento individual (LOUREIRO, 2007). Essa concepção consiste em uma das bases da corrente de EA denominada de conservadora (GUIMARÃES, 2004), que se caracteriza como uma prática reprodutivista das relações de poder existentes, além de não associar as ações de cada indivíduo na sociedade com as condições políticas e históricas (LOUREIRO, 2007).

A EA conservadora segue os padrões da educação tradicional e hegemônica, caracterizada por Paulo Freire (2014) como "educação bancária". Além de possuir um forte viés tecnicista, baseia-se na transmissão de conhecimentos e informações de maneira unidirecional, do professor para o estudante, que termina por ser exclusivamente receptor do conhecimento (GUIMARÃES, 2012). Tal concepção não é epistemologicamente comprometida com o processo de transformações significativas da realidade socioambiental, pois substancia-se nos paradigmas da sociedade moderna e com isso busca encontrar a solução para a crise socioambiental através dos mesmos referenciais que a constituem (GUIMARÃES, 2004).

revista brasileira educação ambiental 
A perspectiva conservadora de educação e de EA é predominante na escola brasileira (GUIMARÃES, 2012). Um dos importantes fatores que a sustentam é a "armadilha paradigmática", que consiste no fato de os professores, mesmo quando bem-intencionados e motivados a inserir as questões ambientais em suas práticas, terem dificuldades em identificar a complexidade da problemática e serem incapazes de fazer diferente (GUIMARÃES 2007; 2012). Dessa maneira, o trabalho docente, mesmo quando realizado por educadores que buscam uma prática crítica, acaba se deparando com limitações a uma prática transformadora (TREIN, 2012). A ausência de uma visão crítica acerca das questões socioambientais atuais e seus campos de disputa geram ações ingênuas por parte dos professores, e consequentemente dos estudantes (GUIMARÃES, 2012), o que dificulta a sua inserção no mundo como sujeitos e potenciais transformadores de sua realidade (FREIRE, 2014).

De forma contrária à educação convencional, a EA crítica é voltada para uma ação reflexiva e coletiva, com conteúdo inserido na realidade socioambiental que vai além das fronteiras da escola, sendo uma educação política, que contribui para a transformação da realidade individual e social de cada um através da luta individual e coletiva (GUIMARÃES, 2007).

A EA crítica possui como origem a pedagogia crítica, que se baseia nos pensamentos emancipatórios e democráticos do pensamento crítico aplicados à educação (CARVALHO, 2004). Essa perspectiva faz parte do mesmo grupo de outras denominações encontradas na literatura, tais como EA transformadora, popular, emancipatória e dialógica, e a sua característica principal consiste na associação entre processos ecológicos e sociais na leitura de mundo e na forma de intervir na natureza (LOUREIRO, 2007).

A proposta da EA crítica considera que para haver transformações significativas é necessário que ocorra de forma recíproca, mudanças individuais e sociais, havendo assim, uma ampliação das possibilidades de transformações, criando opções ao caminho predeterminado pelo modelo hegemônico atual (CARVALHO, 2004; GUIMARÂES, 2007). Sabe-se, contudo, do tamanho da luta que se caracteriza, visto que a construção de utopias que acarretem significativas transformações sociais é influenciada constantemente por forças que buscam ajustar a realidade em direção à conservação do já existente, com o apoio da estabilidade do que já é conhecido (TREIN, 2012).

A produção teórica no Brasil atualmente ocorre de maneira predominantemente crítica, entretanto, no interior das escolas ainda prevalecem as bases conservadoras da EA (GUIMARÃES, 2012). Isso justifica a necessidade de a EA ser estudada, analisada e refletida para que haja 0 cumprimento de forma efetiva dos pressupostos teóricos, e sejam obtidos resultados significativos, alcançando as expectativas criadas sobre a sua atuação (TOZONI-REIS, 2005). 


\section{Percursos metodológicos}

A pesquisa foi realizada no ano de 2014 em uma escola estadual da cidade do Rio de janeiro. Ao redor da escola encontra-se o Parque Estadual da Pedra Branca, que consiste na maior floresta em área urbana do Brasil e uma das maiores do mundo. Essa unidade de conservação possui 12.393 ha e ocupa cerca de $10 \%$ do território da cidade, abrangendo 17 bairros, além de proteger mais de $50 \%$ dos remanescentes florestais da cidade (INEA, 2013).

A escola conta com três turnos, sendo o turno da manhã e o da tarde dedicados ao ensino médio regular, e o noturno dedicado ao EJA - Educação de Jovens e Adultos. Ao todo, os três turnos abrangem 1350 estudantes, divididos em 39 turmas. A escolha dessa escola para o desenvolvimento da pesquisa deu-se por dois fatores principais: a proximidade do Parque Estadual da Pedra Branca, que possui um grande remanescente de Floresta Atlântica em bom estado de conservação, além de ser local de moradia de diversas famílias de agricultores tradicionais, que historicamente resistem com a prática da agricultura urbana; e a existência de uma grande área externa com alguns espaços nitidamente abandonados, que apresentavam um grande potencial para o desenvolvimento de atividades pedagógicas ricas, agradáveis e atrativas para os estudantes.

Tais fatos incitaram a busca da compreensão da realidade da escola, na tentativa de se estimular o desenvolvimento de uma EA comprometida com a realidade socioambiental local e de aproveitar o grande espaço físico existente, o que a cada dia torna-se mais escasso nos centros urbanos.

A metodologia utilizada foi a Pesquisa Participante (BRANDÃO, 2005; TOZONI-REIS, 2005; VIEZZER, 2005), que é orientada a partir da realidade cotidiana dos participantes, os quais devem atuar em todo o processo da pesquisa de maneira crescente (BRANDÃO, 2005). Tal metodologia vai de acordo com a perspectiva crítica da EA, que considera que todos os atores devem atuar em todas as etapas do processo da práxis educativa.

A Pesquisa Participante considera que o conhecimento científico deve articular-se com o popular, ao passo que a relação "sujeito-objeto", entre investigador (educador) e os objetos de investigação (educandos), se transforma em uma relação "sujeito-sujeito" (BRANDÃO, 2005). Tal consideração harmoniza-se com a educação libertadora de Paulo Freire (2014), que implica na superação da contradição educador-educando, de modo que todos se façam simultaneamente educadores e educandos.

Durante essa etapa buscou-se atender as diretrizes sugeridas por Tozoni-Reis (2005) para o desenvolvimento da Pesquisa Participante com qualidade metodológica e relevância social, que são: realização do trabalho de forma coletiva, compartilhada e com valorização do saber não acadêmico; geração de oportunidades concretas de participação dos envolvidos, garantindo-Ihes tomadas de decisão coletivas em todo o processo; produção de conhecimentos ambientais e pedagógicos; busca da superação das 
tendências tradicionais de ensino e educação; abordagem dos temas ambientais de forma ampla; e perspectiva de continuidade para os envolvidos.

A pesquisa foi iniciada em março de 2014 e concluída em julho do mesmo ano. $\mathrm{O}$ primeiro contato com a escola ocorreu com o diretor, que demonstrou interesse pela realização da pesquisa. Antes do início das atividades, foram realizadas duas reuniões com o diretor e com os animadores culturais da escola para organização e planejamento do projeto. Durante essas reuniões, foi feita uma investigação sobre atividades e projetos ligados à EA que pudessem estar ocorrendo ou que já houvessem sido desenvolvidos na escola.

Os dois animadores culturais foram pessoas-chave no desenvolvimento do projeto, atuando de maneira bastante participativa e facilitando a interação com os estudantes. Animação cultural é um cargo que está quase extinto. Foi criado no projeto dos Centros Integrados de Educação Pública (CIEP), na década de 1980, e servia para preencher o tempo integral de permanência na escola e abrir um canal de diálogo e integração da escola com a comunidade, além de, instrumentalizar e possibilitar uma maior difusão de manifestações culturais no interior da escola (Silva, 2008).

Após as primeiras reuniões, foram feitas visitas durante dois dias a todas as turmas do turno da manhã e da tarde, onde o projeto foi apresentado aos estudantes e professores, e eles foram convidados a participar.

O primeiro encontro consistiu em uma roda de discussão e teve como objetivo levantar a definição de alguns conceitos e temas como "meio ambiente" a EA, e desconstruir ideias equivocadas e pouco críticas, que existem em grande parte da sociedade. Foi utilizado um projetor que serviu como recurso didático para a exibição de fotos. As fotos auxiliaram a estimular os alunos a refletir e a questionar quais eram as suas visões e entendimentos sobre os temas.

O segundo encontro consistiu em um debate sobre a relação entre a escola e a comunidade, com destaque para o Parque Estadual da Pedra Branca, que é vizinho da escola.

Após esses dois encontros iniciais, que permitiram o surgimento de reflexões sobre questões socioambientais do bairro, da cidade e da escola, foi sugerido que os alunos realizassem um diagnóstico da escola, incluindo a área externa, que em grande parte raramente é acessada por eles. Essa atividade gerou ótimos resultados e serviu como base para uma rica discussão.

Um momento posterior do projeto consistiu na criação da horta de plantas aromáticas e medicinais. A criação da horta serviu para ocupar parte da área externa inutilizada, gerar uma maior aproximação dos alunos com elementos naturais, e ainda estimular a criação de debates e reflexões sobre diversos temas, como a importância dos saberes tradicionais e sua desvalorização frente aos saberes científicos, etnobotânica, etnofarmacologia, as bases capitalistas das indústrias farmacêuticas e suas consequências para a sociedade, entre outros. Ao todo foram dedicados três encontros para essa Revbea, São Paulo, V. 14, № 2: 86-102, 2019. 
abordagem, que iniciaram com uma aproximação teórica sobre o assunto, acompanhada de uma roda de discussões.

Após a interrupção de aproximadamente dois meses devido às greves e às férias, houve uma desmobilização do grupo caracterizada pela grande diminuição no número de estudantes. No primeiro dia, após interrupção, compareceram apenas três estudantes e no segundo dia apenas duas estudantes e a animadora cultural. Foi realizado um debate sobre os acontecimentos que influenciaram a greve e posteriormente foi feita uma atividade de remoção do capim que cresceu nos canteiros e do lixo que havia na área da horta. Após terminar essas duas atividades, houve uma conversa sobre as atividades que seriam desenvolvidas no segundo semestre e sobre a desmobilização dos estudantes.

Surgiu a hipótese de que se alguns professores reservassem algum tempo das suas aulas para as atividades teóricas e práticas ou participassem do projeto no horário estabelecido, haveria maiores chances de os estudantes voltarem a participar. Essa ideia foi levada para o conselho de classe, mas não teve adesão dos professores, então foi determinado o fim do projeto.

\section{Resultados e Discussão}

\section{Atividades de EA desenvolvidas na escola em momentos anteriores à pesquisa}

Algumas atividades interessantes com enfoque na temática ambiental já haviam sido desenvolvidas na escola a partir do projeto denominado "Tecnologias sustentáveis em escolas públicas de ensino médio no entorno do Parque Estadual da Pedra Branca", realizado pela da Fiocruz - Instituto Oswaldo Cruz em parceria com a UEZO - Universidade Estadual da Zona Oeste. Entre as atividades estão a instalação de uma estação meteorológica que era acompanhada diariamente pelos estudantes, instalação de um aquecedor solar para as torneiras da cozinha e um captador de água da chuva, além da criação de uma pequena horta, que era regada com a água da chuva coletada. $\mathrm{O}$ projeto tinha como objetivo demonstrar a viabilidade destas tecnologias para eficiência energética em escolas públicas.

Essas atividades, apesar de bem intencionadas, foram propostas por agentes externos à escola, de maneira verticalizada e pontual, sem haver uma real integração com o projeto político pedagógico e sem considerar as particularidades da comunidade escolar, ou seja, foi entregue pronto à escola, sem considerar possíveis alterações para se adequar a sua realidade.

A despeito da importância do projeto, os estudantes e funcionários da escola atuaram basicamente como executores das atividades propostas e a maioria das atividades foi temporária ou pontual. Houve um treinamento para capacitar alguns funcionários para a realização de manutenção dos equipamentos, entretanto, tais funcionários eram contratados de empresas terceirizadas e no período de desenvolvimento da pesquisa, já haviam sido substituídos. Desse modo, os projetos não tiveram continuidade e algumas 
instalações como a estação meteorológica, o captador de água da chuva e a horta estavam inutilizados.

Em 2013, por meio do Programa Nacional de Alimentação Escolar com apoio da Rede Carioca de Agricultura Urbana, a escola assinou um contrato para a compra de alguns alimentos da merenda escolar com agricultores do Maciço da Pedra Branca. Essa parceria caracteriza um grande avanço na aproximação da escola com a comunidade local, além do reconhecimento e valorização das tradições agrícolas da região. Através da organização em associações como a Associação de Agricultores Orgânicos da Pedra Branca em Rio da Prata (AgroPrata) e a Associação de Agricultores de Vargem Grande (AgroVargem) e da integração com a Rede Carioca de Agricultura Urbana, os agricultores do Maciço da Pedra Branca tem lutado por políticas públicas que fortaleçam a agroecologia na cidade e tem resistido às grandes forças de expansão urbana, à especulação imobiliária e às políticas preservacionistas dos órgãos ambientais que buscam remover populações tradicionais que habitam a região há mais de cem anos, com o discurso de conservação da natureza (Prado et al., 2012). Essa aproximação pode gerar novas articulações com a comunidade e possibilitar o desenvolvimento de uma escola mais aberta e integrada com o entorno.

\section{Início da pesquisa na escola - $O$ "Projeto Educação Ambiental"}

Em decorrência da EA realizada nas escolas ser, de modo geral, conservadora, um dos principais objetivos da pesquisa era complementar a formação inicial dos estudantes do ensino médio, através dos fundamentos da EA crítica, de modo a construir uma visão mais complexa e reflexiva em relação às questões socioambientais.

Em uma prática educativa crítica, deve-se buscar que os sujeitos envolvidos alcancem a compreensão da sua realidade, o que abre caminhos para a sua transformação. Nessa perspectiva, todos os atores envolvidos devem atuar em todas as etapas do projeto, desde o planejamento até a execução e avaliação (GUIMARÃES, 2012). Essa participação integral faz com que eles se identifiquem com todo o processo e se sintam sujeitos da sua própria história (FREIRE, 2014). A despeito disso, acreditamos que em uma aproximação inicial é necessário que alguns temas e atividades sejam propostos de forma flexível e horizontal, para fomentar as primeiras discussões e alavancar o desenvolvimento do grupo.

\section{Percursos e percalços: reflexões sobre a ação pedagógica de EA na escola}

A diferença no número de estudantes dos dois turnos inscritos no projeto foi muito expressiva. No turno da manhã inscreveram-se 57 estudantes e no turno da tarde inscreveram-se apenas 4. Foi apontado pelos animadores culturais que, em geral, os estudantes da manhã são mais participativos nas atividades extraclasse do que os da tarde, entretanto eles não souberam 
indicar algum motivo possível. Devido ao pequeno número de estudantes do turno da tarde, ficou definido que as atividades seriam realizadas apenas com os estudantes da manhã. Poucos professores mostraram-se interessados pela proposta, apenas uma professora buscou mais informações sobre o projeto, porém participou apenas do primeiro encontro.

Desde o primeiro encontro, a aproximação com os estudantes foi positiva e durante todo o período era nítida a animação em relação à proposta do projeto. $O$ estímulo à reflexão sobre questões socioambientais que permeiam seu cotidiano, como a escola, a região do entorno e seus locais de moradia, despertou interesse e gerou envolvimento com o grupo. As atividades desenvolvidas fora da sala de aula também geraram grande entusiasmo por parte dos estudantes. Diversos estudos de textos e rodas de discussão foram realizados no pátio e no gramado da frente da escola, e além disso, os estudantes realizaram um diagnóstico da escola e do entorno e implementaram uma horta de plantas aromáticas e medicinais.

Outro ponto relevante foi a atuação dos estudantes durante os encontros. Diferente de muitos relatos de professores do ensino básico, os estudantes respeitavam o momento de fala de cada um e ouviam atentamente as ideias e posicionamento dos demais, sem criar muitas conversas paralelas. Tal fato demonstra que, quando os professores garantem a participação ativa dos estudantes nas aulas e quando as aulas são realizadas em espaços que permitem maior interação dos estudantes entre si e com o ambiente, os benefícios são diversos e o processo pedagógico é potencializado.

As principais dificuldades encontradas durante a pesquisa, que podem ser vistas como dificuldades para a inserção da EA na escola sob a forma de projeto, foram: a ausência de apoio dos professores e da direção, que caracterizaram um insulamento do projeto na escola; a grande evasão dos estudantes após a greve de professores e funcionários da rede estadual; a possibilidade de realização do projeto apenas fora do horário regular das aulas.

Nessa ótica, a inserção da EA na escola sob a forma de projeto extraclasse não obteve os resultados esperados. Dentre os fatores supracitados, acredita-se que a desconexão do projeto com o contexto pedagógico e administrativo da escola o caracterizou como uma atividade isolada.

Mesmo com a apresentação inicial do projeto aos professores e o convite para sua participação ter sido reforçado durante um conselho de classe, o notório desinteresse pode ter ocorrido devido à percepção por parte dos docentes de se tratar de mais um projeto como os que chegam à escola, prontos para serem somente executados, a despeito de ter sido explicitada a sua perspectiva horizontal, democrática e colaborativa. Acredita-se ser necessário o envolvimento desses atores chave em todas as etapas do projeto para que haja uma noção de pertencimento, e com isso um real interesse e dedicação no seu desenvolvimento. 
O processo educativo transformador, para que tenha resultados efetivos, necessita da intercomunicação dos diversos atores, ou seja, precisa ser realizado de forma aderida ao movimento da realidade local (FREIRE, 2014). As ideias de Guimarães (2012) ilustram essa concepção, ao afirmar que se quisermos mudar o curso do rio, não adianta criarmos uma corrente fora dele. Esse processo de transformação social não pode ser encarado como um sequenciamento de intervenções pontuais e deve provocar questionamentos, problematizações e transformações de valores, hábitos e atitudes individuais e coletivas no cotidiano da comunidade integrante do processo educativo (GUIMARÃES, 2012).

\section{- Evasão dos estudantes}

A evasão dos estudantes ao longo da pesquisa foi um dos principais determinantes do fim do projeto. Houve uma grande redução inicial, do primeiro para o segundo encontro, porém nos encontros subsequentes, até antes da greve dos professores, que durou de 12 de maio a 28 de junho de 2014, a variação do número de estudantes equilibrou-se em torno de 13 pessoas. Com a greve houve uma drástica redução para 3 estudantes no penúltimo encontro e para 2 no último.

Duas pesquisas sobre a inserção da EA crítica em escolas através de projetos extraclasses encontraram resultados semelhantes em relação à evasão, sem considerar as greves. Moraes (2012), em sua pesquisa de mestrado intitulada "Educação ambiental crítica no cotidiano escolar: uma experiência na formação inicial de professores" iniciou o grupo com a participação de 25 estudantes, porém teve a participação efetiva de 10; Floriano (2011) na pesquisa intitulada "Educação e meio ambiente na Baixada Fluminense: uma proposta de educação ambiental crítica em uma escola de Duque de Caxias - RJ" teve a redução de 35 para 17 estudantes. Segundo o autor, os estudantes justificaram a saída devido ao acúmulo de atividades escolares e pela realização de cursos profissionalizantes, de idiomas e preparatórios para escolas técnicas.

Acredita-se que esse problema esbarra também no fato da não integração da EA no PPP. Tozoni-Reiz (2005) defende a ideia de que a EA crítica deve se basear em um processo contínuo, coletivo e dinâmico de conscientização e participação social para que seja efetivo, e pelo o que pudemos observar, sem a sua inserção no PPP escolar, torna-se inviável garantir a continuidade e real participação dos diversos membros da comunidade escolar.

\section{- Ausência de tempo no horário regular}

A ausência de tempo no horário regular para o desenvolvimento das atividades em EA dificulta que os estudantes possam garantir sua participação contínua ao longo do ano letivo, e muitas vezes impede até que alguns iniciem a participação nessas atividades. Em geral, eles estão acostumados a 
frequentar a escola em apenas um turno e assumem outros compromissos no período que não estão na escola, que vão desde a realização de cursos, como verificado por Figueiredo (2011), cuidados com as tarefas de casa e até mesmo trabalho remunerado para complementar a renda familiar.

Em relação a esse problema, podemos analisar a questão da EA ser tratada como tema transversal ou através de uma disciplina no currículo. As políticas nacionais de EA existentes, como a Política Nacional de Educação Ambiental (PNEA) e os Parâmetros Curriculares Nacionais (PCN), indicam que a EA deve ser trabalhada nas escolas de maneira transversal e não sob a forma de disciplina específica. $\mathrm{Na}$ análise da forma de inserção da EA nas escolas do Brasil e do Sudeste, a disciplina específica foi a maneira menos indicada, com apenas 6\% no Brasil e aproximadamente $9 \%$ no Sudeste (LOUREIRO; COSSIO, 2007).

Todavia, como constatado por Guimarães (2012), atualmente predomina uma perspectiva conservadora de EA nas escolas brasileiras, além de muitas vezes as práticas se restringirem a eventos pontuais como o dia da árvore, a semana do meio ambiente ou palestras e projetos realizados por órgãos externos (Ongs, empresas e universidades). Um dos possíveis motivos para essa realidade é o distanciamento existente entre as propostas legais e a realidade da escola, ou seja, as condições da escola, a jornada de trabalho dos professores (TRISTÃO; RUSCHEINSKY, 2012), que muitas vezes são obrigados a trabalhar em mais de uma escola para completar os tempos de aula ou para complementar o baixo salário.

A escola convencional, da maneira como é difundida no Brasil, baseiase em uma estrutura curricular disciplinar e imobilizada, o que caracteriza um grande desafio para os professores - que também tiveram a sua formação no ensino básico e superior em instituições organizadas de maneira disciplinar desenvolvam a EA de forma interdisciplinar e transversal. Nesse contexto, Loureiro (2006) afirma não ser possível buscar inserir a EA no currículo de maneira transversal, sem compreender a funcionalidade da educação no capitalismo, os mecanismos de permanência e exclusão do estudante na escola, as regras institucionais e as condições de trabalho dos docentes.

A realização da EA através de uma disciplina específica garante um horário regular no currículo, e assim, um desenvolvimento integrado à escola e contínuo ao longo do ano letivo. Essa disciplina pode ser planejada para ser ministrada por mais de um professor, de disciplinas diferentes, garantindo uma abordagem complexa, integrada e interdisciplinar.

Não podemos desconsiderar a possibilidade de trabalhar a EA na forma de disciplina apenas pelo fato das leis indicarem que ela deve ser trabalhada de maneira transversal, pois a existência dessa indicação não significa que ela seja a melhor opção. Layrargues (2003) em sua tese de doutorado faz uma profunda análise da lei no 9795/99 que instituiu a PNEA. O autor demonstra que a PNEA contém características reprodutivistas das condições sociais, visto que o processo educativo proposto por ela tem como meta a mudança cultural

revista brasileira educação ambiental 
e impõe uma visão naturalista de educação, com a omissão de conceitos como conflito, vulnerabilidade e justiça ambiental, que poderiam gerar uma concepção reflexiva da EA e a ampliação do conceito de problema ambiental.

Os principais questionamentos do autor em relação à lei no 9795/99 são: o fato de ela ter sido elaborada por um parlamentar sem a participação de educadores ambientais; a forma precoce com que ela foi implementada, visto que não existiam no Brasil bases políticas e organizacionais dos educadores ambientais, e dessa forma não haviam atores sociais devidamente representados por organizações sociais abrangentes e nem instâncias coletivas de negociação dos interesses e conflitos; a ausência de um campo político e ideológico bem definido acerca das vertentes da EA para que fossem definidas as perspectivas adequadas às instituições brasileiras; a ausência de oportunidades de formação profissional do educador ambiental para que se tenham profissionais com boa base político-pedagógica e conceitual, capaz de orientar o desenvolvimento da EA de forma efetiva nas escolas; a não definição de prazos para o estabelecimento da institucionalização da EA, o que caracteriza a não priorização dessa agenda;

Portanto, essa discussão nos atenta para uma lei nacional que poderia ser um grande avanço para o estabelecimento da EA de forma efetiva nas escolas brasileiras, entretanto termina por dificultar a implementação de um processo pedagógico crítico, reflexivo e comprometido com a transformação social.

\section{Professores desinteressados? Um problema complexo}

A ausência de apoio dos professores, como já apresentado, consistiu em um dos principais fatores limitantes para a garantia da continuidade do projeto ao longo de todo o ano letivo. Esse tópico aborda alguns aspectos dessa realidade, que merecem reflexão.

A aparente apatia e desinteresse dos professores na participação de atividades pedagógicas que vão além das aulas regulares é um importante fator a ser analisado, pois consiste em um grande limitante para 0 desenvolvimento da EA crítica dentro das escolas. Essa situação não pode ser vista como um caso isolado e deve ser analisada sob uma ótica multidimensional, incluída em uma crise do sistema educacional público no Rio de Janeiro e no Brasil como um todo. Antes de abordarmos a questão da EA, devemos analisar um contexto mais amplo desse sistema educacional deficitário.

Darcy Ribeiro, já em 1984, no livro "Nossa Escola é uma Calamidade", analisa diversos aspectos políticos e sociais para compreender o "fracasso educacional" brasileiro. A crise do sistema escolar brasileiro foi agravada com a urbanização, quando 0 avanço e crescimento das cidades foram acompanhados, em proporção, à decadência das escolas públicas (RIBEIRO, 1984). O autor considera essa realidade como uma opção dos governantes, que investiram fortemente em setores como sistema de energia elétrica e a 
construção de estradas, e reduziram os investimentos na educação, o que afeta as escolas, professores e estudantes.

Atualmente, a situação continua semelhante. Dos quase 1,8 milhão de professores da educação básica que atuam na rede pública - incluindo escolas municipais, estaduais e federais - cerca de um quarto, ou seja, 450.000 mantêm contratos temporários ou são terceirizados (NASCIMENTO et al., 2014). Esses profissionais, apesar de realizarem as mesmas funções que os professores concursados, não possuem estabilidade profissional, plano de carreira e outros benefícios acumulados no decorrer dos anos (FERREIRA, 2013).

Além de contratos precários, a desvalorização dessa classe pode ser observada na remuneração. Os professores das escolas públicas ganham em média $52 \%$ menos do que outros profissionais do setor público, $36 \%$ menos do que outros profissionais do setor privado e $19 \%$ menos do que professores da rede privada (LOUZANO et al., 2010). Essa desvalorização da profissão ocorre em consonância com as tendências neoliberais de minimização de gastos nas áreas sociais e afetam severamente a carreira e a vida do trabalhador (FERREIRA, 2013).

A partir desses dados, é possível visualizar a reflexão e denúncia de Darcy Ribeiro sobre a orientação ideológica camuflada por trás da crise do sistema educacional. Ao permitir a decadência da carreira do magistério e a deterioração da rede escolar, se está implementando, ainda que de maneira inconfessável, uma política educacional específica "dos que não querem educar o povo" (RIBEIRO, 1984). Complementando esse pensamento, Darcy Ribeiro propõe que as causas do fracasso educacional brasileiro encontram-se em um grave caso de deficiência intrínseca da sociedade brasileira, em que a classe dominante, ainda com influência do escravismo, compreende o povo como o que há de mais insignificante, visto apenas como força de trabalho, fadada a ser desgastada.

A escola está imersa na sociedade, sendo determinada pelos seus sistemas políticos, econômicos e sociais, e é somente a partir da constatação desses fatos que será possível buscar a superação dessa realidade. É necessário que a sociedade pressione o Estado para o desenvolvimento de uma escola com qualidade. A partir da cobrança de direitos e da defesa da escola, muitos avanços foram conquistados em diversos países da Europa e também em países da América Latina como Chile, Argentina, Uruguai, Costa Rica e México (GADOTTI, 2004).

A classe docente, em grande parte, despertou para esses fatos e tem se organizado para tentar superar essa exploração e desvalorização. Estamos vendo movimentos de luta e resistência dos professores, que têm pressionado o governo em busca de condições dignas de trabalho. No decorrer do desenvolvimento desta pesquisa, os professores da rede municipal e estadual do Rio de Janeiro realizaram uma greve que durou cerca de dois meses e foi fortemente repreendida pelo governo Sérgio Cabral/Luiz Fernando Pezão e

revista brasileira educação ambiental 
pelo prefeito Eduardo Paes, através do corte de salários, ameaças e perseguições políticas, além da repressão violenta da polícia militar em passeatas pacíficas pela cobrança de melhores condições de trabalho e de uma educação de qualidade.

Em 2015, episódios semelhantes aconteceram no estado do Paraná e em São Paulo. Durante uma greve de mais de 40 dias dos professores da rede pública do Paraná, houve um verdadeiro massacre de professores e funcionários por parte da polícia durante um protesto, com mais de 200 pessoas feridas.

Diante desse cenário, pode-se perceber a dimensão do problema que a escola brasileira enfrenta. É possível afirmar que a falta de interesse dos professores na realização de atividades pedagógicas mais complexas, diversificadas e reflexivas é apenas culpa deles, ou será que isso se trata de um sintoma de um sistema educacional em crise?

\section{Considerações Finais}

Através da pesquisa participante, buscou-se implementar em uma escola estadual, um grupo de atividades teórico-práticas sob a perspectiva da EA crítica e contribuir para a formação de pessoas mais reflexivas, críticas e participativas. Pretendia-se também envolver os professores na inclusão dessa perspectiva no cotidiano da escola.

Junto a essa base teórica/ideológica, buscou-se contribuir para a recuperação das áreas externas da escola e dessa maneira estimular os professores às utilizarem em suas atividades pedagógicas. A extrapolação das aulas para além das salas de aula pode garantir um processo de ensinoaprendizagem mais rico e estimulante.

Como apresentado, o projeto teve grande aceitação inicial por parte dos estudantes, entretanto acabou antes do previsto. Apesar de não ter durado até o fim do ano letivo, acreditamos que os encontros contribuíram para o desenvolvimento de uma visão mais complexa para os estudantes acerca dos temas socioambientais.

A expectativa em relação aos professores não foi alcançada, pois eles não se interessaram em participar do projeto. O não envolvimento dos professores foi inclusive uma das principais dificuldades para a perpetuação do grupo.

A partir da análise dos resultados, assim como da bibliografia disponível sobre as formas de inserção da EA na região Sudeste e em algumas partes do Rio de Janeiro, as principais possibilidades que identificamos para a inserção da EA crítica em escolas foram:

- a inserção da EA no PPP escolar, desde que o PPP seja construído de forma coletiva com a comunidade escolar; 
- a realização da EA através de uma disciplina específica, o que garante tempo e espaço para a realização das atividades e não limita a sua abordagem complexa e interdisciplinar, visto que essa disciplina pode ser ministrada por vários professores alternadamente ou em conjunto;

- a superação das fronteiras dos muros da escola e articulação com a comunidade local;

- a garantia da formação continuada dos professores.

Os principais fatores limitantes para a EA crítica foram:

- a fragilidade na formação dos professores, caracterizada pela formação inicial descontextualizada dos aspectos sociais, pela ausência de formação continuada e pela ausência de apoio do governo para a complementação de suas formações com os cursos de mestrado e doutorado;

- a não inserção da EA no PPP e a construção deste pela equipe da direção, com pouca abertura para a comunidade escolar;

- o isolamento da escola em relação à comunidade;

- a indicação das políticas públicas nacionais para a realização da EA de forma interdisciplinar e como tema transversal, sem levar em conta a estrutura predominantemente disciplinar do currículo das escolas e o despreparo dos professores para trabalhar dessa forma;

- a presença de projetos promovidos por empresas, que possuem uma visão conservadora e contribuem para a manutenção dos paradigmas hegemônicos da sociedade capitalista;

- a fragilidade metodológica sobre o tema, mesmo com a grande produção teórica sobre a perspectiva crítica nos últimos anos;

- o distanciamento do material produzido na academia com os professores e diretores das escolas;

- a desvalorização dos professores.

A partir dessas constatações, verificamos que ainda há muitas barreiras a serem superadas para que a perspectiva crítica da EA possa de fato ser incluída nas escolas, e que boa parte delas são problemas estruturais da educação.

\section{Referências Bibliográficas}

BRANDÃO, C.R. Pesquisa Participante. In: JÚNIOR, L.A.F. Encontros e Caminhos: formação de educadoras(es) ambientais e coletivos educadores. Brasília: MMA, Diretoria de Educação Ambiental, 2005. 
CARVALHO, I.C.M. Educação ambiental crítica: nomes e endereçamentos da educação. In: LAYRAGUES, P. P. Identidades da Educação Ambiental Brasileira. Brasília: MMA, 2004.

FERREIRA, D.C.K. Os professores temporários da educação básica da rede pública estadual do Paraná: a flexibilização das contratações e os impactos sobre as condições de trabalho docente. 2013. Dissertação (Mestrado em Educação) - Universidade Federal do Paraná. Curitiba, Paraná.

FIGUEIREDO, C.S.M. Os fazeres da educação ambiental nas escolas da Baixada Fluminense (RJ): um estudo sobre suas práticas e suas concepções. Dissertação (Mestrado). Instituto Federal de Educação, Ciência e Tecnologia do Rio de Janeiro. Programa de Pós-graduação em Ensino de Ciências, 2011.

FLORIANO, M.D. Educação e meio ambiente na Baixada Fluminense: uma proposta de educação ambiental crítica numa escola municipal em Duque de Caxias.. Dissertação (Mestrado). Instituto Federal de Educação, Ciência e Tecnologia do Rio de Janeiro. Programa de Pós-graduação em Ensino de Ciências, 2011.

FREIRE, P. Pedagogia do Oprimido. 56 ed. Rio de Janeiro: Paz e Terra, 2014.

GADOTTI, M. Pedagogia da práxis. 4. Ed. São Paulo : Cortez : Instituto Paulo Freire, 2004.

GUIMARÃES, M. Educação Ambiental Crítica. In: LAYRARGUES, P. P. (Org.). Identidades da educação ambiental brasileira. Brasília (DF): Edições Ministério do Meio Ambiente, 2004.

GUIMARÃES, M. Educação ambiental: participação para além dos muros da escola. In: MELLO, S.; TRAJBER, R. (orgs.). Vamos cuidar do Brasil: conceitos e práticas em educação ambiental. Brasília: MEC/UNESCO, 2007.

GUIMARÃES, M. A formação de educadores ambientais. 8. ed. Campinas: Papirus, 2012.

INSTITUTO ESTADUAL DO AMBIENTE DO RIO DE JANEIRO - INEA. Resumo executivo do plano de manejo do Parque Estadual da Pedra Branca. 2013. Disponível em: <http://www.inea.ri.gov.br/portal/agendas /biodiversidadeeareasprotegidas/unidadesdeconservação/inea 008594.>

Acesso em: 12 de junho de 2017.

LAYRAGUES, P.P. A natureza da ideologia e a ideologia da natureza: elementos para uma sociedade da educação ambiental. Campinas, 2003.

LAYRAGUES, P.P. As desafiantes novidades da educação ambiental: há uma generalizada incompreensão do significado das correntes pedagógicas? In: GUIMARÃES, M. A formação de educadores ambientais. $8^{a}$ ed. Campinas: Papirus, 2012. p. 11-16.

LIMA, G.F.C. Educação Ambiental no Brasil: Formação, identidades e desafios. Campinas: Papirus, 2011. 
LOUREIRO C.F.B. Educação ambiental crítica: contribuições e desafios. In: MELLO, S.; TRAJBER, R. (orgs.). In: MELLO, S.; TRAJBER, R. (orgs.). Vamos cuidar do Brasil: conceitos e práticas em educação ambiental. Brasília: MEC/UNESCO, 2007.

LOUREIRO C.F.B. Educação ambiental e teorias críticas. In. GUIMARÃES, M. (org.). Caminhos da educação ambiental: Da forma à ação. Campinas, SP: Papirus, 2006

LOUREIRO, C. F. B. e COSSíO, M. Um olhar sobre a educação ambiental nas escolas: considerações iniciais sobre os resultados do projeto "O que fazem as escolas que dizem que fazem educação ambiental?". In: MELLO, S.; TRAJBER, R. (orgs.). Vamos cuidar do Brasil: conceitos e práticas em educação ambiental. Brasília: MEC/UNESCO, 2007.

LOUZANO, P.; ROCHA, V.; MORICONI, G.M.; OLIVEIRA, R.P. Quem quer ser professor? Atratividade, seleção e formação docente no Brasil. Est. Aval. Educ., São Paulo, v. 21, n. 47, p. 543-568, set./dez. 2010.

MORAES, P.C. Educação ambiental crítica no contexto escolar: Uma experiência na formação inicial de professores. Dissertação (Mestrado). Instituto Federal de Educação, Ciência e Tecnologia do Rio de Janeiro. Programa de Pós-graduação em Ensino de Ciências, 2012.

NASCIMENTO, P.A.M.M.; CAROLINA, A.S.; SILVA, P.H.D. Subsídios e proposições preliminares para um debate sobre o magistério da educação básica no Brasil. Radar: tecnologia, produção e comércio exterior / Instituto de Pesquisa Econômica Aplicada. Diretoria de Estudos e Políticas Setoriais, de Inovação, Regulação e Infraestrutura. n. 32. Brasília: Ipea, 2014.

PRADO, B.A.; MATTOS, C.; FERNANDEZ, A.C.F. Agricultores do Maciço da Pedra Branca (RJ): em busca de reconhecimento de seus espaços de vida. Agriculturas, v.9, n.2. 2012

RIBEIRO, D. Nossa escola é uma calamidade. Rio de Janeiro: Salamandra, 1984.

SILVA, B.A.R. História da animação cultural nos CIEPS: uma análise sóciohistórica a partir da fala dos idealizadores do programa. Licere, Belo Horizonte. Impresso, v. 11, p. 05-45, 2008.

TEIXEIRA, L.A.; TALAMONI, J.L.B.; TOZONI-REIS, M.F.C. A relação teoria e prática em projetos de educação ambiental desenvolvidos em um bairro de Bauru. Ciência e Educação, Bauru, v. 19, n. 3, p. 657-676, 2013.

TOZONI-REIS, M.F.C. Pesquisa-Ação. In: FERRARO JÚNIOR, L.A. (Org.). Encontros e Caminhos: formação de educadoras(es) ambientais e coletivos educadores. Brasília: MMA, Diretoria de Educação Ambiental, 2005.

TREIN, E.S. Educação ambiental crítica: crítica de que?. Revista Contemporânea de Educação n. 14. ago./dez. 2012. 
TRISTÃO, M.; RUSCHEINSKY, A. A educação ambiental na transição paradigmática e os contextos formativos. In. RUSCHEINSKY, A. A (Org.). Educação Ambiental: abordagens múltiplas. 2.ed. Porto Alegre: Penso, 2012.

VELOSO, N. Entre camelos e galinhas, uma discussão acerca da vida na escola. In: MELLO, S.; TRAJBER, R. (orgs.). Vamos cuidar do Brasil: conceitos e práticas em educação ambiental. Brasília: MEC/UNESCO, 2007.

VIEZZER, M.L. Pesquisa-Ação-Participante (PAP). Encontros e Caminhos: formação de educadoras(es) ambientais e coletivos educadores / Luiz Antônio Ferraro Júnior, org. - Brasília: MMA, Diretoria de Educação Ambiental, 2005. 